KANCHARLA KAMAL KEERTHI CHANDAN, Ph.D. Candidate ${ }^{1}$

(Corresponding author)

E-mail: chandan@uc.pt

ÁLVARO JORGE MAIA SECO, Ph.D. ${ }^{1}$

E-mail: aseco@dec.uc.pt

ANA MARIA CÉSAR BASTOS SILVA, Ph.D. ${ }^{1}$

E-mail: abastos@dec.uc.pt

${ }^{1}$ Centre for Territory, Transport and Environment (CITTA)

Department of Civil Engineering

University of Coimbra, 3030-788, Coimbra, Portugal
Intelligent Transport Systems (ITS)

Preliminary Communication

Submitted: 24 Nov. 2017

Accepted: 2 Oct. 2018

\title{
A REAL-TIME TRAFFIC SIGNAL CONTROL STRATEGY UNDER PARTIALLY CONNECTED VEHICLE ENVIRONMENT
}

\begin{abstract}
The performance of a traffic system tends to improve as the percentage of connected vehicles (CV) in total flow increases. However, due to low CV penetration in the current vehicle market, improving the traffic signal operation remains a challenging task. In an effort to improve the performance of $\mathrm{CV}$ applications at low penetration rates, the authors develop a new method to estimate the speeds and positions of non-connected vehicles (NCV) along a signalized intersection. The algorithm uses CV information and initial speeds and positions of the NCVs from loop detectors and estimates the forward movements of the NCVs using the Gipps' car-following model. Calibration parameters of the Gipps' model were determined using a solver optimization tool. The estimation algorithm was applied to a previously developed connected vehicle signal control (CVSC) strategy on two different isolated intersections. Simulations in VISSIM showed the estimation accuracy higher for the in tersection with less lanes. Estimation error increased with the decrease in $\mathrm{CV}$ penetration and decreased with the decrease in traffic demand. The CVSC strategy with $40 \%$ and higher CV penetration (for Intersection 1) and with $20 \%$ and higher CV penetration (for Intersection 2) showed better performance in reducing travel time delay and number of stops than the EPICS adaptive control.
\end{abstract}

\section{KEY WORDS}

connected vehicles; intelligent transportation systems; real-time traffic signal control; car-following; model calibration; microsimulation;

\section{INTRODUCTION}

In recent years, the connected vehicle (CV) technology has been getting attention as a step towards the next generation transportation system. Traffic signal systems under the CV environment can use real-time communication between vehicles (V2V), vehicles and infrastructure (V2I and I2V) and vehicles and handheld devices (V2D), thus enabling the access to detailed and instantaneous vehicle information such as its speed and location [1, 2].
Such real-time information can be used to design signal control strategies that can efficiently respond to the variations in traffic conditions. In fact, if the CV information is used in real-time traffic signal systems, the performance of the traffic system should improve. Chandan et al. [3] proposed a connected vehicle signal control (CVSC) algorithm for an isolated intersection, which utilized the speeds and positions of the CVs. Various traffic scenarios were tested assuming 100\% CV penetration (CVP).

However, the current main drawback of this technology is that its low market penetration makes it less beneficial to exchange CV information. According to Statista [4], the CVP rates in the year 2017 in various regions of the world were: USA (12.0\%), Europe (5.3\%), Africa and Middle East (2.7\%), Asia (2.7\%), and the forecasted CVP rates for the year 2021 in the same regions are $34.3 \%, 24.3 \%, 20.9 \%$ and $13.3 \%$, respectively.

Furthermore, most traffic signals in the USA are still fixed-time signals [5]. About $18 \%$ of them adopt adaptive traffic control and about $88 \%$ use inductive loop detectors (ILD) [6]. CV-based traffic applications have been only deployed at pilot level [7]. As CV's market penetration will continue to increase over time, the current paper further explores the potential benefits of the CV technology by extending the research of Chandan et al. [3] to evaluate its potential under lower CVPs.

For an effective traffic signal control under low CVPs, it is important to develop methods to acquire vehicle-related information, both spatially and temporally, by using the data provided by the existing infrastructure-based sensors (ILDs or video detectors) and the low penetrated CVs. The ILDs can provide instantaneous information such as vehicles' count, speed and position at any fixed point, for all the vehicles, particularly those not equipped with V2I or V2V communication devices (non-connected vehicles (NCV)). However, they cannot provide vehicle information in a 
geographically continuous way. Hence, the current work proposes a functional alternative that utilizes both the NCV (from the fixed point of the ILDs) and the $\mathrm{CV}$ information to estimate the speeds and the positions of the NCVs and then feed the estimated NCV data to the CVSC algorithm, to adjust the traffic signal timings dynamically and more efficiently.

\section{RELATED WORK}

In recent years, the real-time traffic signal control has captured substantial attention by using the CV data. Many researchers have used the CV data in the processes of estimating vehicle speeds and locations under the different CVPs.

Guler et al. [8] tested the effect of the CVP on their traffic control algorithm, which significantly decreased the average delay as the penetration increased from $0 \%$ to $60 \%$. Benefits were less significant for the penetration rate above $60 \%$.

Goodall et al. [9] proposed a CV-based adaptive signal control algorithm that used a rolling-horizon strategy to choose a phase by optimizing an objective function over a 15-second horizon period. Under low CVPs, the algorithm analyzes deviations in CV's accelerations from those predicted by the car-following model and inserts the NCVs into the simulation network. The simulation gave promising results for penetration rates greater than $50 \%$. However, the algorithm could not estimate the NCVs in the free-flow region where there is almost no interaction between vehicles [10].

Feng et al. [10] proposed a real-time stage allocation algorithm utilizing the CV data and optimized phase sequence and duration by solving a two-level optimization problem. Under low CVPs, the authors applied different traffic models to estimate the NCV's location and speed. The algorithm reduced total delay significantly under high CVPs and was comparable to a standard actuated control under low CVPs. The main limitations in their work are that the estimated NCVs were inserted between a pair of CVs until the gap between the two CVs was full and that the inserted NCV's speed and position were calculated by assuming the acceleration to be zero.

Yang et al. [11] integrated the data from CVs, NCVs and automated vehicles (AVs), and optimized the departure sequence of all vehicles in their algorithm. The arrival sequence, the virtual departure time and the trajectories of the NCVs were estimated using the kinematic wave theory and the Newell's car-following model, based on the information provided by the stopped CVs and AVs. For the CVPs higher than 45\%, the queue length estimation error was within 3 cars. At $50 \%$ and higher, CVP delays and stops were reduced when compared to a standard actuated signal control.
However, the NCV's information was estimated only when the CVs or AVs come to a stop, and not during their motion.

Zheng et al. [5] estimated traffic volumes, particularly for low CVPs (below 10\%), by using the trajectories of the real-world CV data. The estimation problem was formulated as a maximum likelihood problem that incorporates multiple CV trajectories and was solved by using an expectation maximization procedure. The results showed that for volumes estimated at 30-minute and 1-hour intervals, the mean absolute percentage error was within $9-12 \%$, and $19 \%$ at a 10 -minute interval. However, their method did not consider estimating the volumes at a 1-second interval, which can have more potential in utilizing the estimated information to design the signal timings.

The aforementioned studies focused on utilizing Iow CVP data, to estimate the NCV's information and to improve the performance of signal control algorithms, without relying on infrastructure-based detector information. However, it is believed that, during the period of the progressive increase of the CVP in the market, utilizing the vehicle information from both CVs and the existing ILDs, can be an asset in improving the accuracy of the NCV's information estimation. Hence, the current paper builds on the work done by Chandan et al. [3] and tackles the lower CVPs situations by also considering traditional upstream ILD information. The contributions of this paper are twofold. Firstly, a method to estimate the individual NCV's information by using the data from the ILDs and the CVs is proposed. Secondly, the estimated NCV's information is fed into the basic CVSC algorithm for its upgrade. Then, the estimation accuracy and the performance of the upgraded CVSC algorithm are evaluated on two different isolated intersections.

\section{MODELING APPROACH TO ESTIMATE NON-CONNECTED VEHICLE INFORMATION}

The real-time CV information such as speeds and positions of individual vehicles is a valuable resource to develop better signal control strategies. However, the current real-life CVP rate will take a number of years to reach $100 \%$. Under such situations of low CVPs, the ability to estimate speeds and positions of the individual NCVs, spatially and temporally, is important. In this paper, we propose a method to utilize the information from both CVs and ILDs that are typically already installed in the pavement. When a vehicle passes through an ILD, its time of detection $(t)$, order of detection, speed and position information is taken as input to the algorithm. For every time-step after time $t$ until the vehicle crosses the stop-line, the speeds and positions of all the CVs are updated directly, and the 
speed and position of each NCV need to be estimated. To solve this problem, the Gipps' car-following model is adopted.

\subsection{Overview of the Gipps' car-following model}

The Gipps' model belongs to the category of "safety distance" or "collision avoidance" models, where the driver of the following vehicle is assumed to always keep a safe distance from the leading vehicle [12]. According to the Gipps' model, two different speeds are calculated for each vehicle at each time-step. One for the free driving situation, $u_{n}^{a c c}$ (Equation 1) and the other for the car-following situation, $u_{n}^{\text {dec }}$ (Equation 2). The actual speed of the vehicle (Equation 3 ) is chosen to be the minimum of the expressions in Equations 1 and 2. The position of the vehicle is given by Equation 4 [13].

$$
\begin{aligned}
& u_{n}^{a c c}(t+T)=u_{n}(t)+2.5 a_{n} T\left(1-\frac{u_{n}(t)}{u_{n}^{d e s}}\right) \sqrt{0.025+\frac{u_{n}(t)}{u_{n}^{d e s}}} \\
& u_{n}^{d e c}(t+T)=-T d_{n}+ \\
& \sqrt{T^{2} d_{n}^{2}+d_{n}\left\{2\left[x_{n-1}(t)-x_{n}(t)-S_{n-1}\right]-T u_{n}(t)+\frac{u_{n-1}(t)^{2}}{d_{n-1}^{\prime}}\right\}} \\
& u_{n}(t+T)=\min \left\{u_{n}^{a c c}(t+T), u_{n}^{d e c}(t+T)\right\} \\
& x_{n}(t+T)=x_{n}(t)+u_{n}(t+T) T
\end{aligned}
$$

where $u_{n}(t)$ and $u_{n-1}(t)$ are, respectively, the speeds of vehicles $n$ (follower) and $n$ - 1 (leader) at time $t ; x_{n}(t)$ and $x_{n-1}(t)$ are, respectively, the longitudinal positions of the follower and leader at time $t ; u_{n}^{\text {des }}$ and $a_{n}$ are, respectively, the desired speed and maximum acceleration of the follower; $d_{n}$ is the most severe deceleration that the follower wishes to undertake, and $d_{n-1}^{\prime}$ is the most severe deceleration of the leader as estimated by the driver of the follower vehicle $\left(d_{n}>0\right.$ and $\left.d_{n-1}^{\prime}>0\right) . T$ is the reaction time, $S_{n-1}$ is the effective length of the leader, which includes the physical length of the leader and the inter-vehicle spacing at a stop (assumed $6.5 \mathrm{~m}$ ).

\subsection{Estimation of the NCV's information using the Gipps' model}

The speed and the position of the NCVs at the time $t$ is acquired from the ILDs, which are placed in each lane on all the approaches, at $150 \mathrm{~m}$ before the stopline. This position was chosen because it is within the DSRC range (100 m-1000 m) for the CV to share its information [11]. Below, the estimation strategy is explained step-wise.

Step 1: When a vehicle is detected at the time $t$, depending on its type (NCV or CV), the speed and the position information is obtained from the ILDs or the GPS source. As per the time of detection, a lane-wise vehicle database and an order of detection $\left(O_{D}\right)$ are maintained for all the approaches of the intersection.
Step 2: At the time $t+T$, the speed and the position of all the CVs on each lane are updated from the GPS source. If the CV has changed its lane, the speed, the position and the lane-wise $O_{D}$ of all the vehicles on the corresponding approach are updated according to the CV's new position. If the CV has crossed the stop-line, its information is removed from the vehicle database of the corresponding lane and the $O_{D}$ is updated.

Step 3: The estimation of the NCV's information at the time $t+T$ is done using Equations 1-4. However, the estimation equations of the Gipps's model or any other car-following model do not function well in certain traffic situations, in which cases it is justified to adopt other approaches to minimize the estimation error. The traffic scenarios where the Gipps' equations have limitations are described below.

\section{Scenario 1: If the follower has a leader vehicle}

When the signal turns green, the first vehicle in the queue will accelerate only after the reaction time, after perceiving the green light. At this initial time, the actual speed of the follower (NCV) should be zero, with the follower accelerating only after the reaction time, after its leader starts to move. However, the follower's speed, as estimated by the Gipps' model, does not result in zero. During the red interval, when both vehicles are in a stop position, where the actual speeds were zero, the Gipps' equations estimate the follower's speed to be greater than zero. Under such circumstances, to minimize the estimation error, a new equation is proposed to estimate the follower's speed heuristically, as below,

$$
\begin{aligned}
& u_{n}(t+T)= \\
& =\left\{\begin{array}{l}
u_{n}(t), \text { if }\left(u_{n-1}(t)=0 \text { and } u_{n-1}(t+T)=0 \text { and } u_{n}(t)=0\right) \\
u_{n}(t), \text { if }\left(u_{n-1}(t)=0 \text { and } u_{n-1}(t+T)>0\right. \\
\text { and } \left.u_{n}(t)=0 \text { and } R T_{n}(t+T) \leq 1 s\right) \\
u_{n-1}(t+T), \text { if }\left(u_{n-1}(t)=0 \text { and } u_{n-1}(t+T)>0\right. \\
\text { and } \left.u_{n}(t)=0 \text { and } R T_{n}(t+T)>1 s\right)
\end{array}\right.
\end{aligned}
$$

where $R T_{n}(t+T)$ is the reaction time of the follower at the time $t+T$. In this paper, the reaction time was assumed to be 1 second, as this is typically equal to the simulation time-step. This assumption was also based on previous research, which estimated that the reaction time varies within a range of 1.0-1.55 seconds [14].

Scenario 2: If the follower has no leader and if the signal state is green or amber

If the first vehicle in the queue is an NCV when the signal turns green, meaning there is no leader, the driver accelerates the vehicle only after the reaction time, after observing the green signal. In that situation, the Gipps' model does not estimate the speed correctly. Thus, the speed is estimated as: 
$u_{n}(t+T)=$
$=\left\{\begin{array}{l}u_{n}(t), \text { if }\left(u_{n}(t)=0 \text { and } R T_{n}(t+T) \leq 1 s\right) \\ u_{n}(t)+a c c \cdot \Delta t, \text { if }\left(u_{n}(t)=0 \text { and } R T_{n}(t+T)>1 s\right)\end{array}\right.$

where $\Delta t$ is the simulation time-step and $a c c$ is the acceleration of the leaderless NCV, which is applied after the reaction time, after observing the green signal.

Scenario 3: If the follower has no leader and if the signal state is red

When the signal turns red, the first vehicle on the lane will decelerate immediately or after a few seconds depending on the vehicle's speed and distance to stop-line. To analyze this traffic scenario, the roadway is divided into two regions: free-flow region (where vehicles are assumed to always maintain their speed) and slow-down region (where vehicles are assumed to decelerate during the red interval).

If an NCV is the first vehicle in its lane with no leader, it is assumed that the NCV would maintain the same speed as in its previous time-step, if it is located in the free-flow region and if it is in the slow-down region, the NCV is assumed to decelerate until its speed becomes zero at the stop-line, which is proposed in Equation 7.

$u_{n}(t+T)=\left\{\begin{array}{l}u_{n}(t), \text { if }\left(R_{n}(t)=1\right) \\ u_{n}(t)-\operatorname{dec} \cdot \Delta t, \text { if }\left(R_{n}(t)=2\right)\end{array}\right.$

where $R_{n}(t)$ is the region of the follower at time $t$ (1 for free-flow region and 2 for slow-down region), dec is the deceleration of the leaderless follower, which is applied when the follower enters slow-down region during the red interval.

The values of $a c c, d e c$ and the lengths of the freeflow and the slow-down regions are discussed in Section 5. For any traffic scenario other than the ones mentioned above, the Gipps' model is applied to estimate the NCV's speed, using Equations 1-3.

Step 1: At the time $t+T$, the estimated position of the NCV for all the traffic scenarios is calculated using Equation 4. If the NCV's estimated position overlaps with the position of its leader, the estimated position is adjusted without overlapping, including the inter-vehicle spacing at a stop.

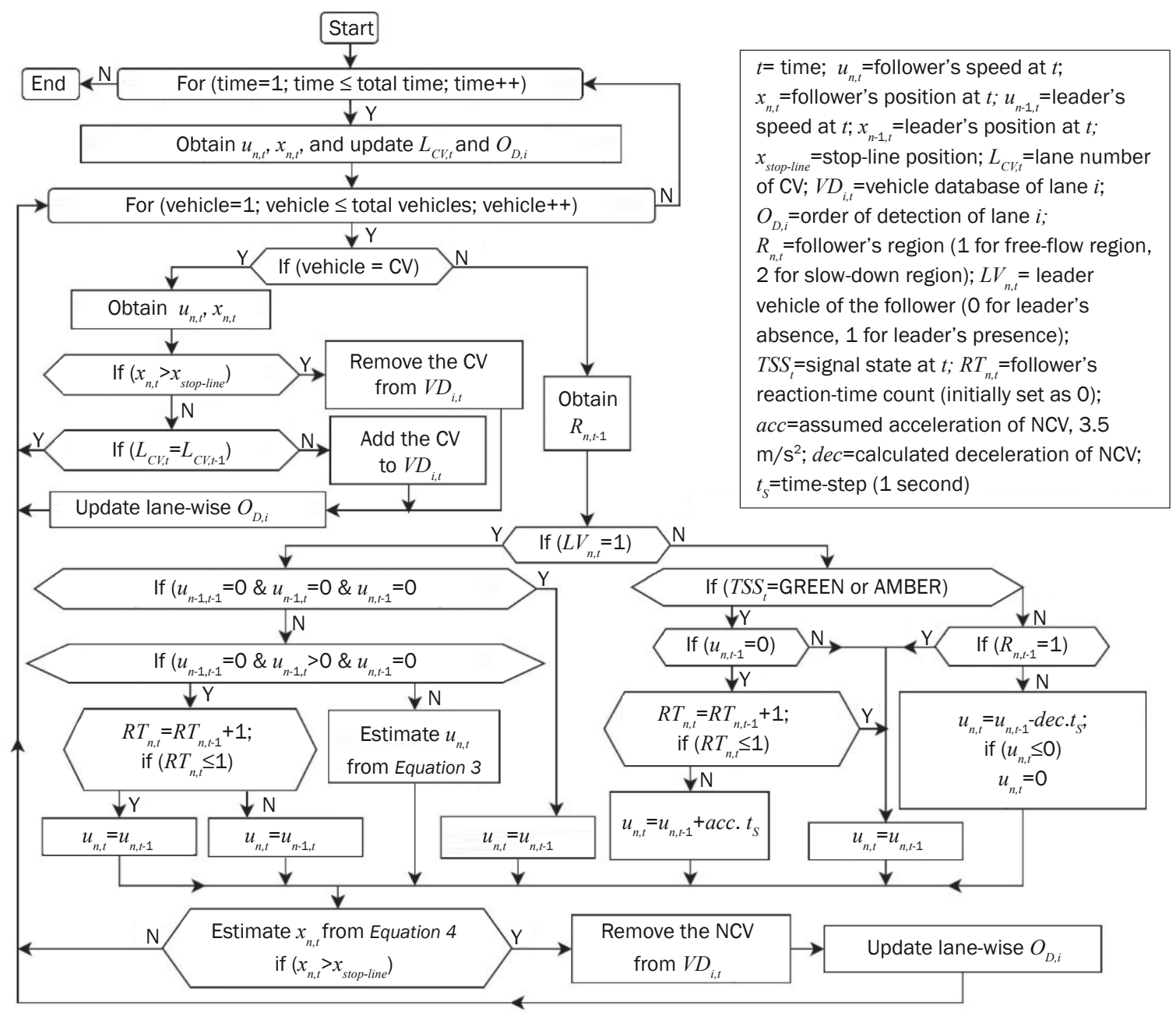

Figure 1 - Flowchart of the estimation process of the NCV information 
Step 2: If the CV's position or the NCV's estimated position crosses the stop-line coordinate, their information is removed from the vehicle database of the corresponding lane and the $O_{D}$ is updated.

It should be noted that the algorithm does not take the NCV's lane changes into consideration. Thus, if in real life an NCV changes its lane, it is assumed to move in the same lane where it was initially detected, until it crosses the stop-line. The flowchart of the estimation algorithm is presented in Figure 1.

\section{BASIC CVSC STRATEGY AND LATEST UPGRADES}

Chandan et al. [3] proposed a real-time traffic signal control algorithm using the CV information (CVSC). This algorithm assumed $100 \%$ of the CVP and used speeds and positions of all vehicles at every time-step. In a phase, green time was provided until the last vehicle that was in the queue during the end of red interval crossed the stop-line. Then, the green time was extended until the average space-mean speed of all vehicles in the current green interval reached $90 \%$ of its desired speed (defined as speed-ratio). During the reserve-time period (Equation 8), the strategy aimed at minimizing the difference between the cumulative arrival and departure flows by maintaining the flow-ratio (Equation 9) on all approaches as near as possible to 1.0 .

$$
\begin{aligned}
& \text { Reserve time }=(\text { Maximum green time } \\
&- \text { Time when the speed ratio reaches } 90 \%) \\
& \text { Flow ratio }=\frac{\sum_{p=1}^{P}(\text { Cumulative departure flow })_{p}}{\sum_{p=1}^{P}(\text { Cumulative arrival flow })_{p}}
\end{aligned}
$$

where $p=$ phase group, $P=$ total number of phase groups.

The basic CVSC algorithm runs based on the real-time CV data collected at every time-step, except for the short duration of the reserve-time. During this period, the algorithm estimated future vehicles' positions using the Wiedemann car-following model and applied the flow-ratio concept only once (to extend the green time), during the start of the reserve-time period. The following significant upgrades were made to this basic CVSC strategy, making this strategy applicable to less than $100 \%$ of the CVP real life environments:

- The NCV information estimation algorithm using the Gipps' model is integrated into the CVSC's, to test the strategy for CVPs lower than 100\%.

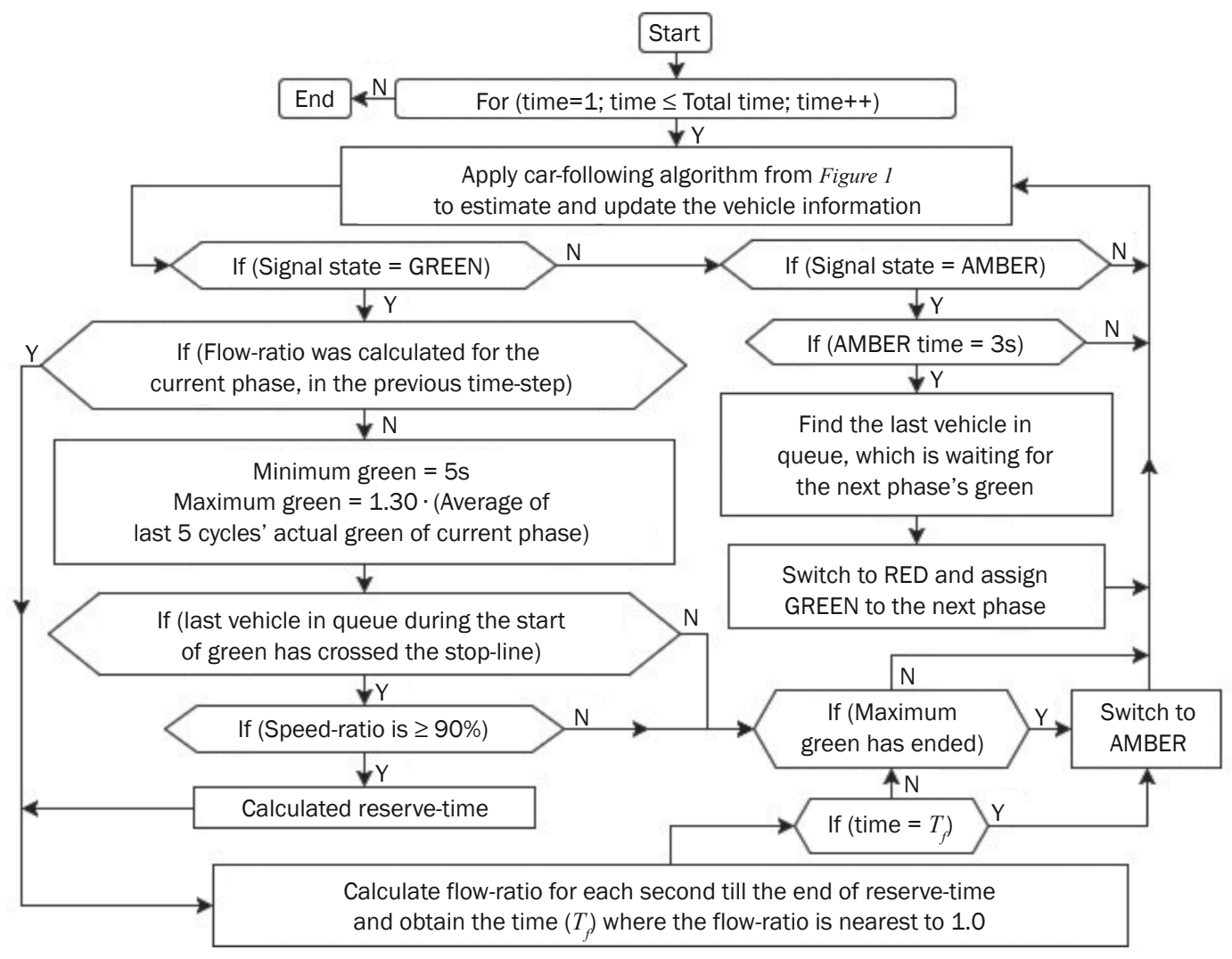

Figure 2 - Flowchart of the updated CVSC algorithm 
- The CV and the NCV information are collected at $150 \mathrm{~m}$ before the stop-line (instead of $300 \mathrm{~m}$ as in [3]) to minimize the estimation error due to lane changes.

- During the reserve-time period, instead of applying the flow-ratio concept only once, it is applied as a rolling-horizon, using the updated CV information at every time-step, until the flow-ratio values stop increasing in comparison to the previous one.

- To investigate the accuracy of the car-following model in estimating the NCV trajectories against the actual vehicle trajectories of VISSIM, the Wiedemann car-following model was replaced by the Gipps' model, but simulations were still performed in VISSIM. It was considered that testing a different car-following behavior against the VISSIM's model would represent real-field testing conditions better and the performance of the CVSC strategy could be assessed in a more robust manner. The flowchart of the updated CVSC strategy is presented in Figure 2.

\section{SIMULATION TESTS AND RESULTS}

\subsection{Simulation framework}

The testing and evaluation of the new CVSC strategy are done by comparison with the EPICS's adaptive control, in VISSIM 8 software [15], which has PTV EPICS [16] signal control module embedded in it. Thus, VISSIM 8 provides a platform for the comparison of the CVSC and the EPICS solution. The CVSC algorithm was coded in $\mathrm{C}++$ language and integrated with VISSIM COM API, which enables users to access the vehicles' speed and position information at every time-step.

Simulations were carried out on two different isolated intersections (Figure 3), one along Castle Downs Road and 97 Street, Edmonton and the other along Sumneytown Pike and DeKalb Pike, Ambler, Pennsylvania. The main reason to choose two different intersections is that, due to the geometrical differences in terms of number of lanes on each approach and the availability of free right-turns, the performance of the NCV estimation algorithm and the CVSC strategy could be assessed in a more robust manner.

Vehicle volumes were converted to approximate intersection saturation rates using the intersection capacity utilization (ICU) metric. The metric sums the amount of time required to serve all movements at saturation for a given cycle length and divides it by that reference. This method is similar to taking a sum of critical volume to saturation flow ratios (v/s), yet allows minimum timings to be considered [17]. To calculate the ICUs, the lost-time per phase, minimum green time and the reference cycle length were assumed as 4, 5 and 120 seconds, respectively. The field-recorded volumes produced 0.65 and 0.75 ICU across Intersections 1 and 2 , respectively. These original volumes were altered by uniform factors to generate volumes of 0.35, 0.50, 0.80, $0.95 \mathrm{ICU}$, respectively, as shown in Table 1. The turning movements were allocated to four different phases, namely, phase 1 (NBT, NBR, SBT, SBR), phase 2 (NBL, SBL), phase 3 (EBT, EBR, WBT, WBR) and phase 4 (EBL, WBL). The movements EBR, WBR, NBR and SBR on Intersection 1 have dedicated right turns.

In both the CVSC and the EPICS solutions, a fourphased timing plan was applied within a cycle and the simulation was run for 1 hour, in which the first 15 minutes were used as a warm-up period. The results of various scenarios are based on the average of 10 random speeds. Cars (95\%), buses (3\%) and heavy goods vehicles (HGVs) (2\%) were used in the simulation, whose minimum and maximum desired speeds were taken as $48-58 \mathrm{~km} / \mathrm{h}, 40-45 \mathrm{~km} / \mathrm{h}$ and $40-45$ $\mathrm{km} / \mathrm{h}$, respectively.

For the traffic Scenario 2 (in Section 3.2), when the traffic signal turns green, the first vehicle in the queue accelerates $(a c c)$ starting from the rest. Previous research suggests acceleration values for starting
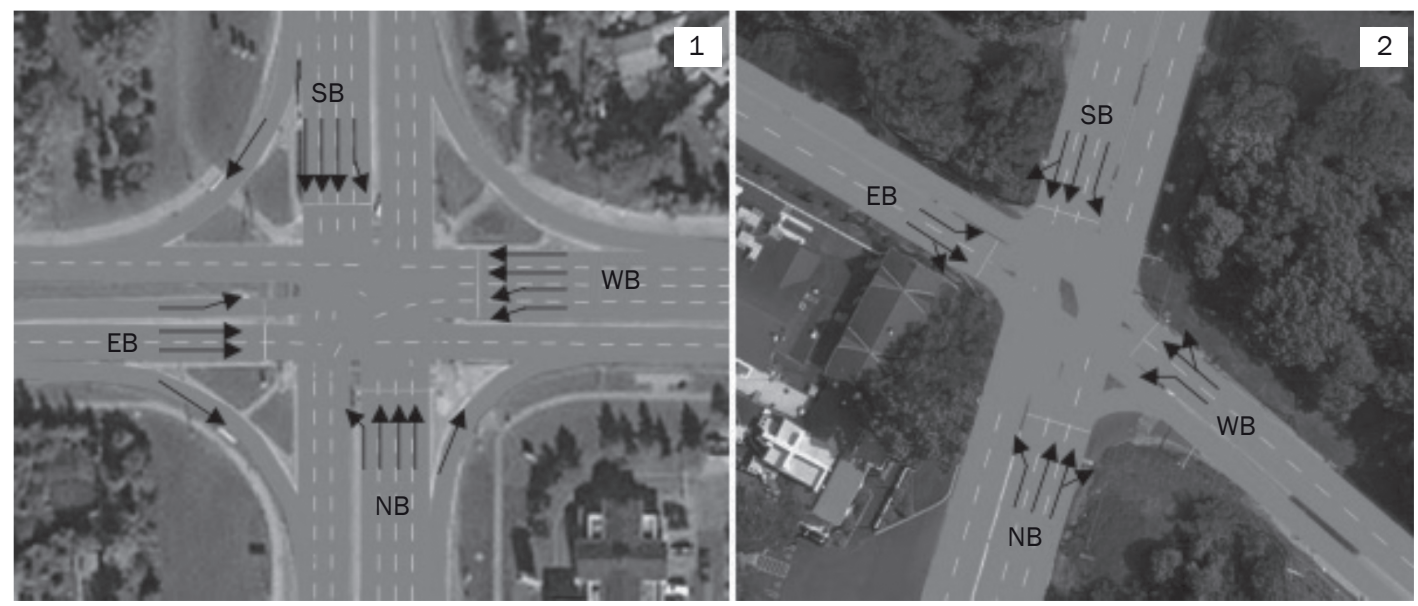

Figure 3 - Snapshot of test Intersections 1 and 2 [Source: Bing maps] 
Table 1 - Tested volumes along Intersections 1 and $2[18,19]$

\begin{tabular}{|c|c|c|c|c|c|c|c|c|c|c|c|c|}
\hline \multirow{2}{*}{ ICU } & \multicolumn{12}{|c|}{ Turning movements at Intersection 1} \\
\hline & EBL & EBT & EBR & WBL & WBT & WBR & NBL & NBT & NBR & SBL & SBT & SBR \\
\hline 0.35 & 35 & 296 & 99 & 159 & 225 & 103 & 244 & 514 & 239 & 108 & 452 & 268 \\
\hline 0.50 & 50 & 423 & 141 & 228 & 322 & 148 & 348 & 735 & 341 & 154 & 645 & 383 \\
\hline 0.65 & 65 & 550 & 183 & 296 & 418 & 192 & 453 & 955 & 443 & 200 & 839 & 498 \\
\hline 0.80 & 80 & 677 & 225 & 364 & 514 & 236 & 558 & 1,175 & 509 & 246 & 1,033 & 613 \\
\hline 0.95 & 95 & 804 & 267 & 433 & 611 & 281 & 662 & 1,396 & 605 & 292 & 1,226 & 728 \\
\hline \multirow{2}{*}{ ICU } & \multicolumn{12}{|c|}{ Turning movements at Intersection 2} \\
\hline & EBL & EBT & EBR & WBL & WBT & WBR & NBL & NBT & NBR & SBL & SBT & SBR \\
\hline 0.35 & 6 & 109 & 10 & 38 & 100 & 17 & 15 & 148 & 77 & 34 & 293 & 28 \\
\hline 0.50 & 12 & 230 & 21 & 80 & 210 & 36 & 32 & 310 & 161 & 71 & 616 & 58 \\
\hline 0.65 & 17 & 336 & 30 & 116 & 306 & 53 & 46 & 453 & 235 & 103 & 899 & 85 \\
\hline 0.80 & 22 & 429 & 39 & 148 & 391 & 68 & 59 & 579 & 300 & 132 & 1,149 & 108 \\
\hline 0.95 & 26 & 517 & 47 & 179 & 471 & 82 & 71 & 698 & 362 & 159 & 1,385 & 131 \\
\hline
\end{tabular}

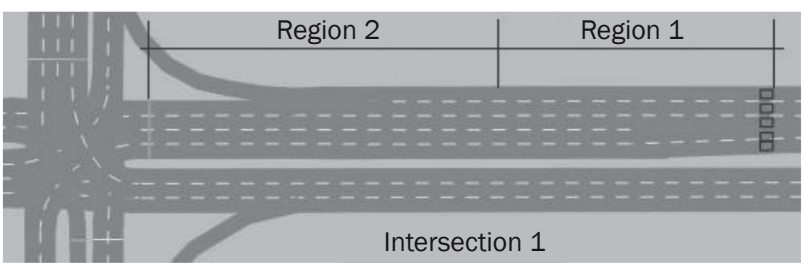

Figure 4 - Slow-down and free-flow regions on Intersections 1 and 2

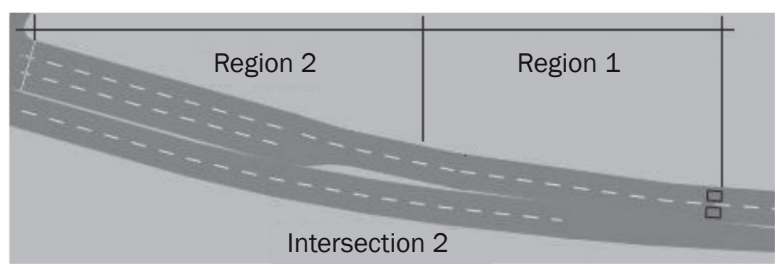

calibrate the Gipps' model parameters. The second evaluates the prediction accuracy of the NCV information estimation algorithm and the third evaluates the signal control performance of both the CVSC and the EPICS solutions.

\subsection{Calibration procedure for the Gipps' model parameters}

To estimate the speed and position of the NCVs, the Gipps' car-following model was applied (Equations 1-4), in which $a_{n}, d_{n}, d_{n-1}^{\prime}$ are the calibration parameters. As in Soria et al. [14], the calibration analysis in this paper was performed in EXCEL using the solver optimization tool. The range of calibration parameters for the optimization was taken as $a_{n}=[0,3.3] \mathrm{m} / \mathrm{s}^{2}$ and $d_{n} \approx d_{n-1}^{\prime}=[1.5,5] \mathrm{m} / \mathrm{s}^{2}$. The parameters were calibrated by minimizing the root mean square error (RMSE) for the speed difference between the actual value (from VISSIM) and the estimated value (from Gipps'), with the constraints on the considered ranges of $a_{n}$ and $d_{n}$.

Calibrations were performed on 10 randomly selected leader-follower pairs, on both intersections. The Gipps' model estimated the speed and the position information with lower RMSE for lower ICUs. The average values of $a_{n}$ and $d_{n}$ for Intersection 1 were $3.3 \mathrm{~m} / \mathrm{s}^{2}$ and $3.6 \mathrm{~m} / \mathrm{s}^{2}$ for $0.95 \mathrm{ICU}$, respectively, and $1.3 \mathrm{~m} / \mathrm{s}^{2}$ and $3.6 \mathrm{~m} / \mathrm{s}^{2}$ for $0.35 \mathrm{ICU}$, respectively. For Intersection 2 , the average values were $2.9 \mathrm{~m} / \mathrm{s}^{2}$ and 
$2.9 \mathrm{~m} / \mathrm{s}^{2}$ for $0.95 \mathrm{ICU}$, respectively, and $0.5 \mathrm{~m} / \mathrm{s}^{2}$ and $3.7 \mathrm{~m} / \mathrm{s}^{2}$ for $0.35 \mathrm{ICU}$, respectively. These calibrated values were considered in the NCV's information estimation algorithm.

\subsection{Analysis of the estimation accuracy of the Gipps' car-following model}

\subsubsection{Evaluation methodology}

To analyze the NCV's estimation accuracy spatially, the approach that is critical in both intersections was selected and divided into 2 regions before the stop-line: Region 1 (150 m-80 m) and Region 2 (80 m-0 m), as shown in Figure 4.

Considering the vehicle arrival pattern (Poisson distribution) in VISSIM, the estimation accuracy was analyzed temporally, by dividing the simulation time of 900-3600 seconds into three 15-minute intervals. Three performance indicators, namely, average speed RMSE, average position RMSE and average percentage lane change of NCVs were used in each region. For all the NCVs at time $t$, in region $k$, the average difference between the actual value (from VISSIM) and the estimated value (from the Gipps' model) was calculated and it was averaged over each 15-minute time interval. The governing equations are:
Average speed $R M S E, u_{k, I}=\frac{\sum_{t=1}^{I}\left(\sqrt{\sum_{i=1}^{N} \frac{\left(u_{i, a c t}^{k}-u_{i, e s t}^{k}\right)^{2}}{N^{k}}}\right)_{t}}{I}$

Average position RMSE, $x_{k, I}=\frac{\sum_{t=1}^{I}\left(\sqrt{\sum_{i=1}^{N} \frac{\left(x_{i, a c t}^{k}-x_{i, e s t}^{k}\right)^{2}}{N^{k}}}\right)_{t}}{I}$

Average percentage lane change of $N C V s, L_{k, I}=$

$$
\sum_{t=1}^{I} \frac{\sum_{i=1}^{N}\left(\frac{L C_{i}^{k} \cdot 100}{N^{k}}\right)_{t}}{I}
$$

where, $t=$ time, $I=$ interval time (900 seconds), $i=\mathrm{NCV}$ count, $N^{k}=$ total number of the NCVs in region $k, u_{i, a c t}^{k}$, $u_{i, \text { est }}^{k}, x_{i, a c t}^{k}$ and $x_{i, \text { est }}^{k}$ are the actual speed, estimated speed, actual position and estimated position of the NCV $i$ in region $k, L C_{i}^{k}=$ actual number of lane changes made by the NCV $i$ in region $k$.

\subsubsection{Results from Intersection 1}

At 0.95 ICU and $80 \%$ CVP, the average speed and position RMSEs in Regions 1 and 2 were $4.7 \mathrm{~km} / \mathrm{h}$ and $6.0 \mathrm{~km} / \mathrm{h}$, and $4.3 \mathrm{~m}$ and $8.9 \mathrm{~m}$, respectively, with an average percent of the NCV's lane change of $11.3 \%$ and $12.0 \%$, respectively. As the NCV's lane change at

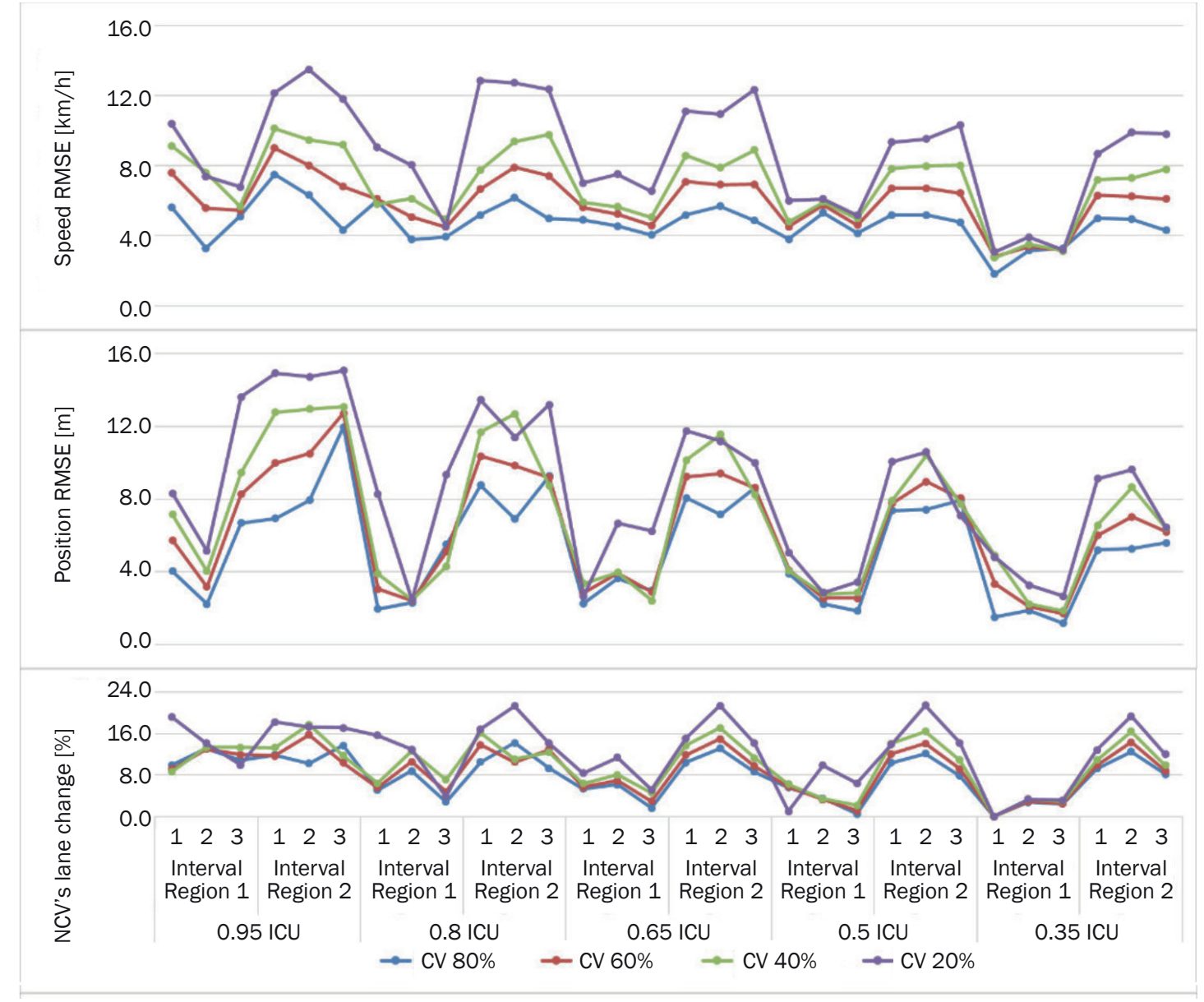

Figure 5 - Estimation accuracy for Intersection 1 
any time-step is not estimated, it affects the estimation of its speed and position throughout the simulation period. The following can be said from the estimation accuracy results presented in Figure 5:

1) For a given ICU, with the decrease in the CVP, as the proportion of the NCVs increases, the average speed and position RMSEs and the percent lane change of the NCVs also increase in both Regions 1 and 2 (which was also observed for Intersection 2).

2) For a given CVP, with the decrease in the ICU, the proportion of the NCVs in total flow decreases, and the average percent lane change of the NCVs and the average speed RMSE in Regions 1 and 2 decreases.

3) For a given CVP, at any ICU, the average percent lane change of the NCVs and the average speed RMSE in Region 1 was lower than in Region 2. This is because during the red interval when vehicles were arriving to the stop-position, due to the availability of 3 lane choices for through-movement
(NBT), the vehicles in Region 2 tend to choose the lane (or fill the gap of the lane) which has a smaller queue.

4) For all the ICUs and all the CVPs, the average position RMSE in Region 1 was lower than in Region 2 (which was also observed for Intersection 2). As the NCVs move forward from the detection point, the position RMSE gets accumulated with time.

\subsubsection{Results from Intersection 2}

At 0.95 ICU and 80\% CVP, the average speed and position RMSEs in Regions 1 and 2 were $5.4 \mathrm{~km} / \mathrm{h}$ and $4.4 \mathrm{~km} / \mathrm{h}$, and $5.4 \mathrm{~m}$ and $8.5 \mathrm{~m}$, respectively, with an average percent of the NCV's lane change of $2.2 \%$ and $0.9 \%$, respectively. At higher ICUs, Intersection 2 showed higher estimation RMSE, compared to Intersection 1 . The following can be concluded from the results presented in Figure 6:

1) For a given CVP, at higher ICUs, the average percent lane change of the NCVs in Region 1 was higher than in Region 2, and vice versa at lower ICUs. This

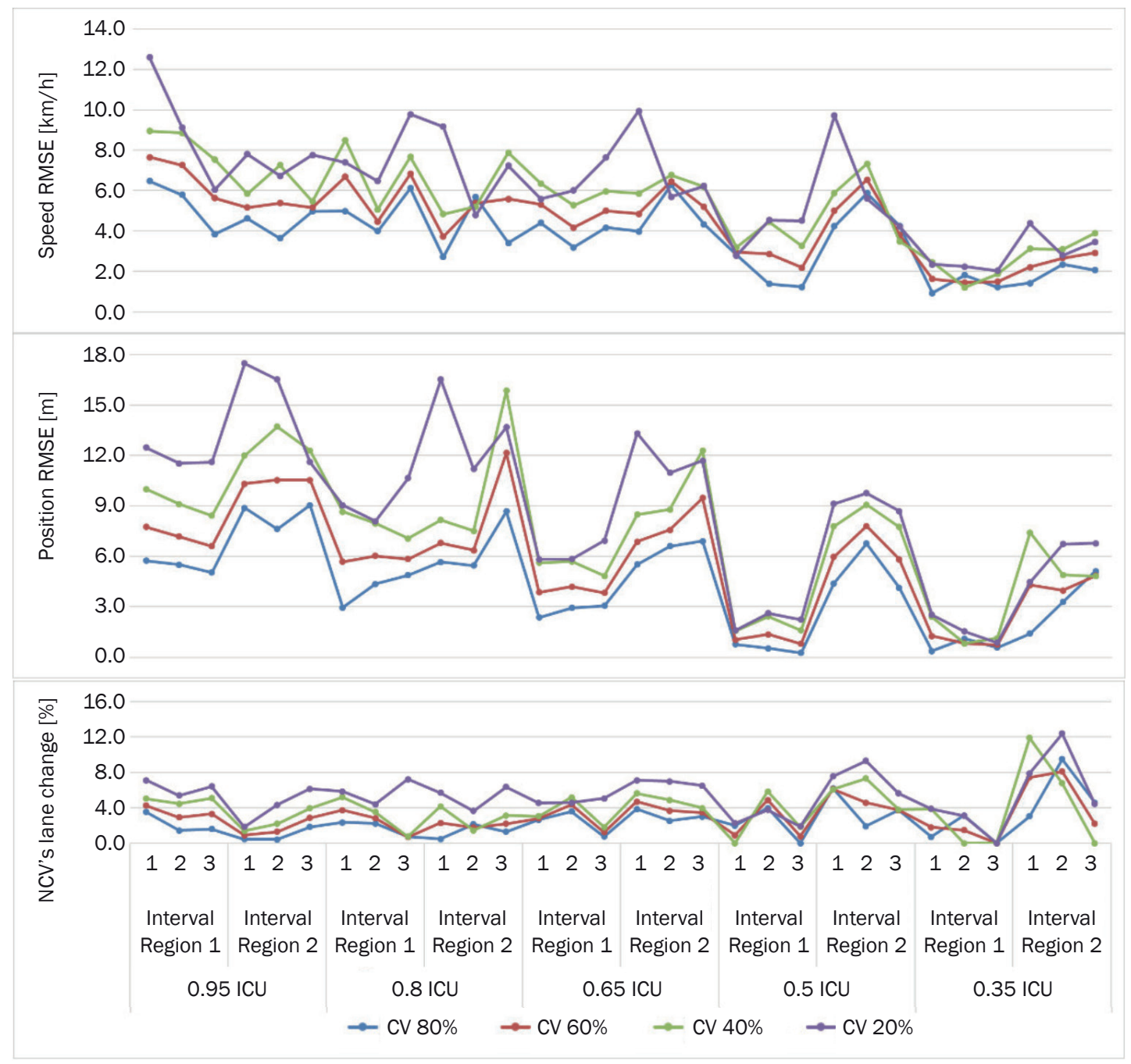

Figure 6 - Estimation accuracy for Intersection 2 
is because, due to the availability of only two-lane choices for both through and right-turning movements (SBT, SBR), vehicles tend to choose their lanes earlier at higher ICUs. At lower ICUs, during the red-interval, the through-movement vehicles have more freedom to choose to stop in the lane where there is a smaller queue.

2) For a given CVP, with the decrease in the ICU the average percent lane change of the NCVs decrease in Region 1 and increase in Region 2 (justification as in 1).

3) For a given CVP, at higher ICUs, the NCV's average speed RMSE in Region 1 was higher than in Region 2 , and vice versa at lower ICUs (justification as in 1).

Results from both intersections were consistent, although, due to higher number of lanes on the critical approach of Intersection 1 and the free right-turning lane, the average percent lane changes of the NCVs are higher on Intersection 1. Hence, as expected, the average speed and position RMSEs were also higher in Intersection 1. It was also observed that, as expected, the difference in percent lane changes of the NCVs between Regions 1 and 2 is higher in Intersection 1 . In general, the performance of the estimation algorithm was better at lower ICUs, due to lower proportion of the NCVs and lower percent lane change of the NCVs. Finally, for the traffic situations where the Gipps' equations have limitations, it was observed that the newly proposed equations were able to reduce the speed and position estimation RMSEs.

\subsection{Analysis of the CVSC strategy results}

To compare the results of both the CVSC and the EPICS solutions, travel time delay and average number of stops per vehicle were used as measures of effectiveness (MOEs), which are shown in Figure 7 for both intersections. Table 2 presents the percentage difference in the performance of the CVSC strategy against the EPICS solution.

For Intersection 1, for 100\% CVP rate at various ICUs, CVSC strategy has reduced travel time delay by $8.4 \%-24.3 \%$ and average number of stops by $3.8 \%-$ $10.3 \%$, compared to the EPICS solutions. As expected, benefits decrease with the decrease in CVP. At 40\% and higher CVP rates, for all ICUs, CVSC strategy has performed better than EPICS, reducing the MOEs. At ICUs lower than 0.5, even the CVSC strategy with 20\% CVP has shown better results.

For Intersection 2, for $100 \%$ CVP rate at various ICUs, CVSC strategy has reduced travel time delay by $5.2 \%-24.3 \%$ and average number of stops by $3.9 \%-$ $20.4 \%$, compared to EPICS, with higher benefits at higher ICUs. At 20\% and higher CVPs, for all the ICUs, CVSC strategy has outperformed the EPICS solution. The benefits were higher with higher CVPs at higher ICUs. For a given ICU, at all CVPs, travel time delay and average number of stops were higher for Intersection 2 due to the lower number of lanes and bigger queues on Intersection 2. But, generally, the results for both intersections are consistent.

\section{CONCLUSIONS AND FUTURE WORK}

This paper improves the algorithm from Chandan et al. [3] by (1) developing a new method to estimate speeds and positions of the NCVs for real-life situations where the CV penetration is lower than 100\%; (2) upgrading the basic CVSC strategy by including an NCV's estimation algorithm. Furthermore, the accuracy of the estimation algorithm and the performance of

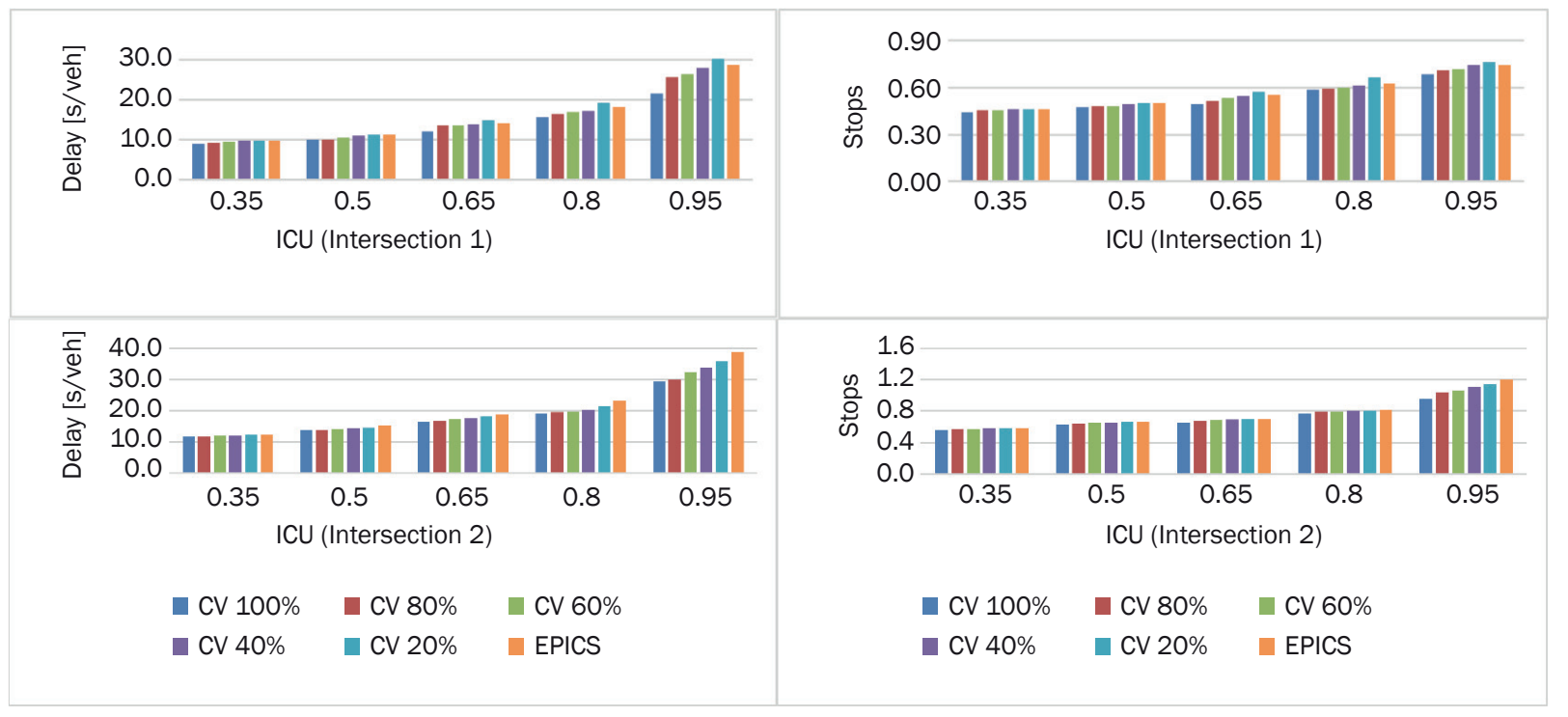

Figure 7 - CVSC performance for a range of CVPs and ICUs on Intersections 1 and 2 
Table 2 - Performance of CVSC strategy against EPICS solution

\begin{tabular}{|c|c|c|c|c|c|c|c|c|c|c|}
\hline \multicolumn{11}{|c|}{ Percent change of travel time delay compared to EPICS [\%] } \\
\hline & \multicolumn{5}{|c|}{ Intersection 1} & \multicolumn{5}{|c|}{ Intersection 2} \\
\hline ICU & 0.35 & 0.50 & 0.65 & 0.80 & 0.95 & 0.35 & 0.50 & 0.65 & 0.80 & 0.95 \\
\hline EPICS & 0.0 & 0.0 & 0.0 & 0.0 & 0.0 & 0.0 & 0.0 & 0.0 & 0.0 & 0.0 \\
\hline CVSC (100\%) & 8.4 & 12.0 & 13.0 & 14.4 & 24.3 & 5.2 & 10.5 & 11.9 & 17.4 & 24.3 \\
\hline CVSC (80\%) & 6.1 & 10.7 & 3.0 & 9.5 & 10.6 & 4.2 & 9.9 & 9.6 & 15.5 & 21.9 \\
\hline CVSC (60\%) & 2.6 & 6.1 & 2.4 & 7.6 & 8.0 & 3.3 & 9.0 & 7.1 & 13.5 & 16.7 \\
\hline CVSC (40\%) & 1.9 & 1.4 & 0.8 & 5.6 & 2.0 & 2.5 & 7.2 & 5.5 & 11.8 & 13.1 \\
\hline CVSC (20\%) & 0.7 & 1.0 & -5.8 & -5.6 & -6.0 & 1.2 & 4.4 & 3.0 & 6.9 & 7.3 \\
\hline \multicolumn{11}{|c|}{ Percent change of average number of stops per vehicle compared to EPICS [\%] } \\
\hline & \multicolumn{5}{|c|}{ Intersection 1} & \multicolumn{5}{|c|}{ Intersection 2} \\
\hline ICU & 0.35 & 0.50 & 0.65 & 0.80 & 0.95 & 0.35 & 0.50 & 0.65 & 0.80 & 0.95 \\
\hline EPICS & 0.0 & 0.0 & 0.0 & 0.0 & 0.0 & 0.0 & 0.0 & 0.0 & 0.0 & 0.0 \\
\hline CVSC $(100 \%)$ & 3.8 & 6.0 & 10.3 & 6.3 & 8.0 & 3.9 & 6.2 & 7.6 & 6.0 & 20.4 \\
\hline CVSC (80\%) & 2.1 & 4.5 & 7.3 & 5.1 & 4.5 & 2.7 & 3.3 & 5.6 & 3.8 & 13.9 \\
\hline CVSC (60\%) & 1.8 & 4.1 & 3.2 & 3.8 & 3.2 & 1.7 & 2.3 & 3.1 & 2.7 & 10.7 \\
\hline CVSC (40\%) & 0.6 & 1.7 & 1.0 & 2.3 & 0.3 & 1.0 & 2.0 & 2.3 & 2.1 & 7.4 \\
\hline CVSC (20\%) & 0.4 & 0.9 & -4.0 & -6.1 & -2.9 & 0.4 & 0.9 & 1.3 & 1.8 & 4.2 \\
\hline
\end{tabular}

the upgraded CVSC algorithm was evaluated on two different intersections, thus producing a more robust evaluation.

The estimation algorithm obtains speed and position information of the NCVs from the ILDs, placed in each lane at $150 \mathrm{~m}$ before the stop-line and that of the CVs at all times, between $150 \mathrm{~m}$ and $0 \mathrm{~m}$ before the stop-line. At every time-step the algorithm estimates the speed and the position of the NCVs using the Gipps' model, assuming that the NCVs do not change their lanes. For certain traffic situations where the Gipps' equations do not function well, heuristic equations were applied to reduce the estimation error.

Simulations were performed on two real-field isolated intersections using the VISSIM 8 software. Calibration parameters of the Gipps' model were determined for each intersection, at different ICUs, by minimizing the RMSE, using the solver optimization tool in EXCEL. The estimation results showed that the average speed and position RMSEs increased with the decrease in the CVP and decreased with the decrease in the ICU.

Both real-time CV and estimated NCV information are now taken in consideration by the CVSC strategy, which sets the green time by serving the queue that was identified during the red interval and maintaining the flow-ratio as near as possible to 1.0. Simulations showed higher benefits with higher CVPs at higher ICUs.

In general, the estimation algorithm performed well. However, as lane-changing behavior of the NCVs was not considered, benefits were higher for the intersection with less lanes. The estimation algorithm requires the NCV information at least once when it enters the road network. Hence, currently the algorithm is applicable in isolated intersections with upstream ILDs or any sensors that can detect all vehicles, lanewise. Detectors can be placed within 150-250 m from the stop-line, but, the closer to it they are placed, the less the occurring lane changes, and, thus, the better the estimation accuracy.

Nonetheless, there is room for improvement of the NCV's information estimation algorithm, justifying future research. First, only one second was used for drivers' reaction time and simulation time-step, meaning it should be evaluated if there is a need for calibration if the road environment is different, namely by applying smaller time-steps. Second, it is also worth investigating drivers' deceleration decision-making behavior, particularly when the vehicle is far from the stop-line during the end of the amber period, to improve the accuracy of the method used to determine the location of free-flow and slow-down regions. Finally, work should focus on a method to identify the NCVs' lane-changing behavior and integrating it to the CVSC strategy.

\section{ACKNOWLEDGMENT}

The authors would like to acknowledge the Portuguese Foundation for Science and Technology (FCT), for the support of PhD scholarship SFRH/ BD/51536/2011, under MIT-Portugal Program and the PTV Group for providing the EPICS software.

\section{KANCHARLA KAMAL KEERTHI CHANDAN,}

Estudante de Doutorado ${ }^{1}$

E-mail: chandan@uc.pt

ÁLVARO JORGE MAIA SECO, Ph.D., Professor Associado ${ }^{1}$

E-mail: aseco@dec.uc.pt 
ANA MARIA CÉSAR BASTOS SILVA, Ph.D.,

Professora Auxiliar ${ }^{1}$

E-mail: abastos@dec.uc.pt

${ }^{1}$ Centro de Investigação do Território, Transportes e Ambiente (CITTA), Departamento de Engenharia Civil Universidade de Coimbra, 3030-788, Coimbra, Portugal

\section{ESTRATÉGIA DE CONTROLO DE SINAIS LUMINOSOS EM TEMPO REAL APLICADA A AMBIENTES COM NÍVEIS PARCIAIS DE COBERTURA DE VEÍCULOS CONECTADOS}

\section{ABSTRATO}

O desempenho do sistema de tráfego tende a melhorar à medida que aumenta a percentagem de veículos conectados (CV) em circulação. No entanto, e pelo facto do nível de penetração de CV no atual sistema de transportes permanecer reduzido, a otimização do sistema de regulação do trânsito, por esta via. releva-se uma tarefa desafiadora. Procurando melhorar o seu nivel de desempenho global mesmo em ambientes com baixos niveis de presença de $\mathrm{CV}$, os autores desenvolveram um novo método para estimar as velocidades e posições de Veículos Não-Conectados (NCV) aplicável em interseções semaforizadas. O algoritmo usa informação continua dos CV presentes nas correntes de tráfego, e de velocidades e posições iniciais de NCVs a partir de detetores fixos locais, para estimar os movimentos sucessivos dos NCVs recorrendo ao modelo de seguimento de Gipps. Os parâmetros de calibração do modelo de Gipps foram estimados recorrendo à ferramenta de otimização Solver. O novo algoritmo de estimação de NCVs foi incorporado numa estratégia pré-existente de controlo em tempo real de sistemas semaforizados baseada em veículos conectados (CVSC), e foi testado em duas diferentes interseções isoladas. Simulações desenvolvidas no software de microssimulação VISSIM mostraram melhores resultados na aplicação à interseção com menos vias de aproximação. $O$ erro de estimativa aumentou com a diminuição do nível de penetração CV e diminuiu com a diminuição dos fluxos de tráfego. A estratégia CVSC resultou num melhor desempenho, comparativamente ao sistema de controlo adaptativo EPICS, para niveis de penetração CV superior a $40 \%$ na interseção 1, e para um nível de penetração CV superior a 20\% na interseção 2, reduzindo quer o tempo de viagem quer o número de paragens.

\section{PALAVRAS-CHAVE}

Veículos conectados; Sistemas inteligentes de transporte; Controlo semafórico em tempo real; Modelo de seguimento; Calibração de modelos; Microssimulação;

\section{REFERENCES}

[1] Huang L, Yao J, Wu W, Yang X. Feasibility analysis of vehicle-to-vehicle communication on suburban road. Promet - Traffic \& Transportation. 2013;25(5): 483-493.

[2] Connected vehicles. 2017. [cited 2017 Nov 14]. Available from: http://www.its.dot.gov/cv_basics/index.htm

[3] Chandan K, Seco AM and Silva AB. Real-time traffic signal control for isolated intersection, using car-following logic under connected vehicle environ- ment. Transportation Research Procedia. 2017;25: 1613-1628.

[4] Statista. The Statistics Portal. 2017 Aug. [cited 2017 Nov 14]. Available from: https://www.statista.com/ outlook/320/100/connected-car/worldwide

[5] Zheng J, Liu HX. Estimating traffic volumes for signalized intersections using connected vehicle data. Transportation Research Part C: Emerging Technologies. 2017;79: 347-362.

[6] Knowledge resources. 2013. [cited 2017 Nov 14]. Available from: http://www.itsdeployment.its.dot.gov/ summaries.aspx

[7] Connected vehicle pilot deployment program. 2017. [cited 2017 Nov 14]. Available from: https://www.its. dot.gov/pilots/index.htm

[8] Guler SI, Menedez M, Meier L. Using connected vehicle technology to improve the efficiency of intersections. Transportation Research Part C: Emerging Technologies. 2014;46: 121-131.

[9] Goodall NJ, Park B, Smith BL. Microscopic estimation of arterial vehicle positions in a low-penetration-rate connected vehicle environment. Journal of Transportation Engineering. 2014;140(10): 04014047.

[10] Feng Y, Head KL, Khoshmagham S, Zamanipour M. A real-time adaptive signal control in a connected vehicle environment. Transportation Research Part C: Emerging Technologies. 2015;55: 460-473.

[11] Yang K, Guler SI, Menendez M. Isolated intersection control for various levels of vehicle technology: Conventional, connected, and automated vehicles. Transportation Research Part C: Emerging Technologies. 2016;72: 109-129.

[12] Casas J, Ferrer JL, Garcia D, Perarnau J, Torday A. Traffic simulation with Aimsun. In: Barceló J. (eds) Fundamentals of traffic simulation. International series in operations research \& management science. Vol 145. New York, USA: Springer; 2010. p. 173-232.

[13] Vasconcelos L, Neto L, Santos S, Silva AB, Seco Á. Calibration of the Gipps car-following model using trajectory data. Transportation Research Procedia. 2014;3: 952-961.

[14] Soria I, Elefteriadou L, Kondyli A. Assessment of car-following models by driver type and under different traffic, weather conditions using data from an instrumented vehicle. Simulation modelling practice and theory. 2014;40: 208-220.

[15] VISSIM 8 User manual. Germany. PTV Planung Transport Verkehr AG, 2017.

[16] EPICS User manual. Germany. PTV Planung Transport Verkehr AG, 2017.

[17] Husch D, Albeck J. Intersection Capacity Utilization: Evaluation Procedures for Intersections and Interchanges. Albany, CA: Trafficware; 2003.

[18] Traffic volumes and turning movements. 2015. [cited 2017 Nov 14]. Available from: http://www.edmonton.ca/transportation/traffic_reports/traffic-volumes-turning-movements.aspx

[19] Traffic counts. 2015. [cited 2017 Nov 14]. Available from: http://www.dvrpc.org/webmaps/trafficcounts/

[20] Wang J, Dixon K, Li H, Ogle J. Normal Acceleration Behavior of Passenger Vehicles Starting from Rest at All-Way Stop-Controlled Intersections. Transportation Research Record: Journal of the Transportation Research Board. 2004;1883: 158-166

[21] Bogdanović V, Ruškić N, Papić Z, Simeunović M. The 
research of vehicle acceleration at signalized intersections. Promet - Traffic \& Transportation. 2013;25(1): 33-42.

[22] Rittger L, Schmidt G, Maag C, Kiesel A. Driving behaviour at traffic light intersections. Cognition, Technology \& Work. 2015;17(4): 593-605.
[23] Viti F, Hoogendoorn SP, van Zuylen HJ, Wilmink IR, van Arem B. Speed and acceleration distributions at a traffic signal analyzed from microscopic real and simulated data. Proceedings of the $11^{\text {th }}$ International IEEE Conference on Intelligent Transportation Systems, 12-15 Oct 2008, Beijing, China; 2008. p. 651-656. 